Illinois State University

ISU ReD: Research and eData

Theses and Dissertations

$7-9-2020$

\title{
Managing Citizen Engagement: Local Leader Perspectives From A Midwestern Small City
}

Isabella B. Green

Illinois State University, greenbbella@gmail.com

Follow this and additional works at: https://ir.library.illinoisstate.edu/etd

Part of the Sociology Commons, and the Urban Studies and Planning Commons

\section{Recommended Citation}

Green, Isabella B., "Managing Citizen Engagement: Local Leader Perspectives From A Midwestern Small City" (2020). Theses and Dissertations. 1288.

https://ir.library.illinoisstate.edu/etd/1288

This Thesis is brought to you for free and open access by ISU ReD: Research and eData. It has been accepted for inclusion in Theses and Dissertations by an authorized administrator of ISU ReD: Research and eData. For more information, please contact ISUReD@ilstu.edu. 


\section{MANAGING CITIZEN ENGAGEMENT: LOCAL LEADER}

\section{PERSPECTIVES FROM A MIDWESTERN SMALL CITY}

ISABELLA B. GREEN

\section{Pages}

Small cities, with their mix of urban capacity and small-town charm, are a promising environment for interactive and inclusive citizen engagement. However, small cities have received very limited attention by sociological and planning literature, and even less attention has been paid to the leaders of small city communities. This study contributes to this gap through an analysis of the dynamics of participation between small city leaders and their constituents from the leaders' perspective. Studying up through interviews with planners and officials of a midwestern small city, this study examines how small city leaders pursue citizen engagement while managing the bureaucratic expectations of their work. This study found structural constraints within the work including organizational, methodological, political and social expectations that expended functionaries' capacity to conduct robust citizen engagement.

KEYWORDS: citizen engagement, collaborative planning, public participation, small cities 
MANAGING CITIZEN ENGAGEMENT: LOCAL LEADER

PERSPECTIVES FROM A MIDWESTERN SMALL CITY

ISABELLA B. GREEN

\author{
A Thesis Submitted in Partial \\ Fulfillment of the Requirements \\ for the Degree of \\ MASTER OF SCIENCE \\ Department of Sociology and Anthropology \\ ILLINOIS STATE UNIVERSITY
}

2020 
(C) 2020 Isabella B. Green 
MANAGING CITIZEN ENGAGEMENT: LOCAL LEADER

PERSPECTIVES FROM A MIDWESTERN SMALL CITY

ISABELLA B. GREEN

COMMITTEE MEMBERS:

Michael L. Dougherty, Chair

Frank D. Beck 


\section{ACKNOWLEDGMENTS}

I would first like to thank my thesis advisor Dr. Michael L. Dougherty of the Department of Sociology and Anthropology. Mike has been an invaluable mentor through this process. His door and email inbox were always open to the many questions that have come up over these last two years.

I would also like to acknowledge Dr. Frank D. Beck of the Department of Sociology and Anthropology and the Stevenson Center for Community and Economic Development as the second reader on this thesis. I am grateful for Frank's valuable comments and thoughtful appreciation for this topic.

I would also like to thank Beverly Beyer, Senior Associate Director of the Stevenson Center for Community and Economic Development, for her gracious assistance and support in advocating for my project.

Finally, I would like to express my profound gratitude to my partner and friends who provided unfailing support and continuous encourage throughout my years of study and through the process of researching and writing this thesis. This accomplishment would not have been possible without them.

I. B. G. 


\section{CONTENTS}

Page

ACKNOWLEDGMENTS

$\begin{array}{ll}\text { CHAPTER I: INTRODUCTION } & 1\end{array}$

The Nature of Local Government Work in Small Cities 1

CHAPTER II: SMALL CITY DEVELOPMENT, A REVIEW OF THE LITERATURE 4

Economic Trajectories of Small Cities in the 21st Century 4

$\begin{array}{ll}\text { The Growing Diversity of Small Cities } & 6\end{array}$

$\begin{array}{ll}\text { Small City Multi-Modal Transportation } & 7\end{array}$

Politically Driven Community Development Strategies 7

Collaborative Planning Theories of Citizen Engagement $\quad 8$

CHAPTER III: STUDYING THE MEANING-MAKING PROCESSES OF SMALL CITY LEADERS 12

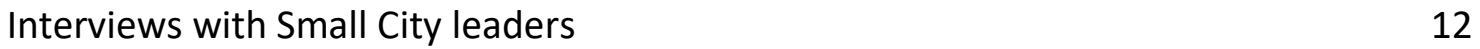

$\begin{array}{ll}\text { Content Analysis of Planning Documents } & 13\end{array}$

$\begin{array}{ll}\text { Considerations for Interviewing Elites } & 14\end{array}$

$\begin{array}{ll}\text { Inductive Analytic Approach } & 15\end{array}$

$\begin{array}{ll}\text { Limitations } & 17\end{array}$

$\begin{array}{ll}\text { Woodridge: A Profile } & 18\end{array}$

CHAPTER IV: ASSESSING THE OCCUPATIONAL EXPECTATIONS AND CONSTRAINTS OF

$\begin{array}{ll}\text { THE WOODRIDGE LEADERS } & 21\end{array}$

Leaders as the Swiss Army Knife of the Community 22

The Standard Operating Procedures of Engagement 25 
$\begin{array}{ll}\text { Appeasing Stakeholders } & 29\end{array}$

Reaching the Hard to Reach 32

$\begin{array}{ll}\text { CHAPTER V: SUMMARY } & 38\end{array}$

A Discussion of How Small City Leaders Make Sense of Constraints in their

$\begin{array}{ll}\text { Work } & 38\end{array}$

Recommendations for Improving Small City Government Practices 39

Conclusion: The Future of Small City Governance $\quad 42$

$\begin{array}{ll}\text { WORKS CITED } & 45\end{array}$

APPENDIX A: LETTER TO RESEARCH PARTICIPANTS

APPENDIX B: INFORMED CONSENT FORM

APPENDIX C: SEMI-STRUCTURED INTERVIEW GUIDE 


\section{CHAPTER I: INTRODUCTION}

\section{The Nature of Local Government Work in Small Cities}

Local governments constitute the majority of U.S. government entities and employ a vast population of civil functionaries and elected officials to direct municipal initiatives. Tasked with representing community interests, these leaders manage competing obligations including the presumed expectation that they will generate inclusive, robust citizen engagement. However, a trend of civic disengagement in municipal politics and development challenges their assumed responsibility for promoting local democracy, enforcing equitable policies, and providing a high quality of life for everyone in the community.

The nature of local government work is highly technocratic. Functionaries are expected to be highly educated in a wide variety of technical responsibilities. They are also assumed to be expedient in their work to make efficient use of their city's limited funding and resources. This creates tension as local leaders seek to reconcile the bureaucracies of their work with the capriciousness of democracy and public participation. This study explores how small city functionaries make sense of conflicting expectations to be broadly accountable to the citizenry while remaining rational and efficient in their work.

I consider these meaning-making processes by researching up, building my analysis from in-depth interviews with small city leaders and supplemental content analysis of long-range planning documents. Collaborative planning theory shaped the approach I took to developing and addressing my research aims. Long-regarded as foundational theories of urban planning, Sherry Arnstein and John Friedmann's models informed my understanding of robust, inclusive, and citizen-driven public participation. 
This study centers on populated yet little understood semi-urban communities known as small cities. Also referred to as third-tier cities, medium-sized cities, semi-urban locales, or the metro hinderlands, small cities occupy a significant portion of the US urban landscape (Erickcek and McKinney 2004; Nevarez and Simons 2019; Siegel and Waxman 2001), with a growing number of urbanites are living and working in small city communities of 200,000 or fewer residents (2010 US Bureau of the Census).

Seeking a contemporary definition, this study applies Jon Norman's criteria for small city designation to explore the occupational expectations of local leaders in mid-sized communities (2013). Norman defines small cities according to size, proximity, and qualitative criteria. Most small cities have continued to increase in population over the preceding twenty-five years, but some small cities such as Youngstown, Ohio are the result of larger cities losing population. Norman defines small cities as having a population between 50,000 and 200,000 residents. Norman distinguishes small cities from similarly sized communities according to measures of proximity and qualitative attributes. Suburban sprawl and bedroom communities of big cities can have similar populations, but their close proximity to a similarly sized or larger city disqualifies them as proper small cities. Suburban communities can also lack the small town feeling with big city amenities characteristic of small cities.

The site of this research in a small city was a deliberate choice. Small cities are a semiurban classification that contains both the charm of a small-town and the liveliness of a metropolis. A balance of neighborly intimacy and cosmopolitan diversity, small cities are a promising environment for local leaders to cooperate with the public to achieve community development goals. 
Despite their significant presence across the urban landscape, the overwhelming consensus of small city experts is that our understanding of these semi-urban communities is incredibly limited (Bell and Gripshover 2007; Bell and Jayne 2009; Brennan, Hackler and Hoene 2005; Irion 2007; Pitt and Basset 2013; Ramsey, Michalos and Eberts 2016; Robertson 1999). Small city experts corroborate that small cities have nuanced assets, challenges, and opportunities that are not addressed in studies of larger cities (Buenker and Mesmer 2003; Frye 2017; Ocejo, Kosta, and Mann 2019). Despite a limited understanding of these mid-sized urban communities, small cities will hold greater political and economic influence in the coming decades as their populations grow, communities diversify, and economies develop (Norman 2013; Siegel and Waxman 2001).

This study contributes to a growing body of literature on the functionality of small cities and the livelihood of their inhabitants. Through interviews with local leaders, I offer a nuanced analysis of the occupational expectations and constraints of small city local government. Drawing on recent developments in urban planning theory and models of practice, I assess the community engagement processes of small cities from the perspective of functionaries leading these participatory efforts. 


\section{CHAPTER II: SMALL CITY DEVELOPMENT, A REVIEW OF THE LITERATURE}

Small cities occupy a significant portion of the U.S. urban landscape, yet the nuances of their social structures and functionality remain understudied and underrepresented in urban planning research. David Bell and Mark Jayne, for example, argue that there is a bias in the literature on the basis of sizism that leads to small cities being underrepresented (2009). Of the accounts available, the consensus is that small cities are not monolithic; they are best studied individually and with the understanding that recommendations are not universal. That said, much of what is known about small cities focuses predominantly on growth factors related to economic development and downtown revitalization. The remaining literature highlights the importance of community identity, transportation networks, ethnic diversity, and education (Bell and Jayne 2009; Ramsey et al. 2016).

\section{Economic Trajectories of Small Cities in the 21st Century}

There is great variety across the economies of small cities that is a direct result of macroeconomic changes, namely the shift from predominantly manufacturing to service sector employment. Many small city communities have had to reexamine their assets and adapt according (Norman 2013). Some have focused on economic attributes and amenities that emphasize the community's established culture and priorities. Others rebranded, centering their economic identity around a new industry, the downtown, or the local university. (Siegel and Waxman 2001).

Small cities who lacked the means to shift their economic focus over the last fifty years were less resilient. For example, communities who lost their major employer, college towns whose students out-migrated, and bedroom communities overwhelmed by sprawl are among 
those who often experienced economic decline (Erickcek and McKinney 2004). Economic difficulties were particularly high for small cities clustered closely together who had to compete with surrounding cities for big box retailers (Bell and Gripshover 2007).

The rise of tourism has motivated many small cities to focus on "destination branding" efforts to improve the look and function of their downtowns (Baker 2019). This includes economic campaigns to improve a small city's sense of place such as historic preservation, improved walkability, or downtown nightlife (Frye 2017). These cosmetic and experiential improvements are aimed at boosting local consumption by offering modest amenities for residents and tourists (Paradis 2000; Robertson 1999). In turn, downtown redevelopment attracts new businesses that are drawn by certain "pull factors," such as wayfinding infrastructure, a cohesive community identity, and a strong consumer base, that signal a high quality of place (Segendy 1997).

While critical to the economic health of many small cities, downtown revitalization efforts can be a "complex and disordered process" for the government officials tasked with leading them (Frye 2017). As a result, policy-makers of small cities tend to prioritize development projects they have greater control over, such as sidewalks and crosswalks or community events, rather than more capricious tasks such as attracting new businesses or increasing jobs (Bias, Leyden, and Zimmerman 2015).

Community colleges and universities also significantly shape small city economies, both in serving as a stabilizing anchor during hardship and in promoting growth in the regional economy (Green 2007; Siegel and Waxman 2001). Educational attainment, in conjunction with income and job growth, has been used as an indicator of small city well-being (Siegel and 
Waxman 2001). However, high educational attainment depends on a small city retaining their college graduates with attractive job prospects and convenient amenities (Erickcek and McKinney 2004; Henderson 2017).

\section{The Growing Diversity of Small Cities}

An influx of immigrants, young adults, and LGBTQ residents have shaped the demographic profile and diversity of small cities, especially since the turn of the century. These groups are drawn by the cosmopolitan amenities, economic opportunities, and affordable housing prices of small cities.

Small cities house increasing numbers of LGBTQ individuals, representing a large population of those living outside of larger cities. Local progress on the front of LGBTQ support and inclusivity is often framed as an big city phenomenon, but many small cities have started to reserve inclusive spaces for the community to congregate (Forstie 2019). More specifically, gay bars of small cities have become critical social amenities for members of the LGBTQ community (Mattson 2019).

A rise in immigrant population has contributed to the growing demographic and economic diversity of small cities (Norman 2013). Pushing for inclusivity, a notable number of small cities and micropolitan counties have declared themselves sanctuary cities (Griffith and Vaughan 2019). However, the growing immigration population has also revealed major shortcomings of small city capacity. Many communities lack the resources to adequately provide support in the form of language support and other human services, and immigrant voices are largely missing from civic participation (Siegel and Waxman 2001). 


\section{Small City Multi-Modal Transportation}

Small city infrastructure caters predominantly to automobiles, but rising populations have necessitated multi-modal options including bike lanes, bus routes, and train stops. For the many small cities that emerged during the manufacturing age, their origins were a strategic decision to be located near a major highway, train line, or water access point. Small cities have since grown to be a mix of the car dependency of small-town America and the downtown walkability of larger cities (Adams and Van Drasek 2007). Public transportation is common but less prevalent and extensive as financial constraints and lower demand limit small cities' network of trails, bike lanes, bus routes, and train stops. While limited, non-automobile forms of transportation are critical means of mobility for college students, low-income and elderly residents (Irion 2007).

\section{Politically Driven Community Development Strategies}

The mid-range size of small cities enables its government leaders to implement emergent urban development strategies and technology with more rapid implementation. These include small scale smart growth and sustainable infrastructure. In an effort to improve transparency and cooperation with the public, small city leaders have grown their online presence and use of digital tools. However, growing momentum in these areas is contingent on small cities' political capacity and funding.

Small city governments have successfully implemented smart growth strategies and clean energy initiatives. Smart growth, or smart city techniques, involve use of technological tools and resources to increase the quality and convenience of community amenities for residents. These strategies first emerged in larger cities who have the infrastructure and 
resources to pursue large-scale projects, but small cities are still "competitive in this space" because of their ability to start small, move quickly, and scale up (Lam and Wagner Givens 2018: 36; Poltie, Udoh, and Luna-Reyes 2020).

Larger cities were early adopters of clean energy initiatives, but small cities have since started to pursue clean energy opportunities such as alternative energy sources or city-wide recycling. The success and scale of these initiatives is dependent on sufficient funding, political backing, and aligned community values. High adopters included small cities who openly and routinely collaborated with community members and stakeholders to ensure the projects were in line with constituent interests (Pitt and Basset 2013).

Progress on small city government innovation is contingent on sufficient funding, meaning that efforts can be easily stunted by restricted municipal budgets. The growing populations and burgeoning economies of small cities necessitate formal planning and development departments, but small city municipal budgets lack the ability to delegate and specialize responsibilities that larger cities have. This leads to what Roy Buck and Robert Rath refer to as small cities' "municipal poverty" that leads to oversubscribed government workers, a disinvestment in new development, and insufficient resources to do comprehensive community planning (Mattson 1994).

\section{Collaborative Planning Theories of Citizen Engagement}

This study draws from urban planning theory and applies it to the small city context. Collaborative planning is a widely accepted model for encouraging cooperative and citizeninformed community development. This approach, sometimes referred to as transactive planning or communicative planning, stresses that leaders and citizens engage within equitable 
channels of communication that stress sincerity, legitimacy, truthfulness, and comprehensibility (Habermas 1984; Innes 1995). Patsy Healy (1997) applies this criteria and finds that citizen outreach efforts often fall short of open debate.

John Friedmann (2011) foregrounds the implication of language and meaning for collaborative planning theory. He argues that planners and their constituents communicate in vastly different ways. Planners speak in formal terms according to routine and protocol that can be easily translated into official documents. Constituents, who Friedmann refers to as "unspecified client-actors," communicate with more descriptive comments derived from personal experiences. Clients feel pressured to communicate according to the formalities of the planners. To bridge the differing communication style of the two parties, collaborative planning theory encourages open, authentic conversations that address specific and shared concerns.

Sherry Arnstein's (1969) "ladder of citizen participation" provides a helpful heuristic tool for talking about gradations and nuance within participatory planning. Although subsequently criticized for its assumed linear hierarchy and lack of practical guidance (Collins and Ison 2009; Tritter and Morallum 2006), Arnstein's classic ladder reminds us that citizen power must be at the heart of participatory planning. Arnstein likens incremental levels of citizen authority over community progress to rungs on a ladder. Each increasing rung moves engagement away from condescending or manipulative practices on the part of local leaders and towards citizens inclusion and negotiation. As Arnstein summarizes, "citizen participation is a categorical term for citizen power" (2019: 24), but to achieve these higher levels of the citizen participation ladder, both parties need to contribute. Local leadership must be willing to forgo some of their decision-making authority and citizens need to commit time and energy towards engagement. 
Friedmann advocates for similar improvements, critiquing what he observes as a growing disregard for public interest on the part of local leadership. He argues that citizens should hold responsibility for decisions that affect their community's quality of life (2007).

Collaborative planning theories are oft-cited by community developers and urban planners, but these ideas offer little pragmatic guidance for implementing participatory and citizen-oriented engagement. Arnstein and Friedmann remain prominent references for planning theory but their ideas, rooted in mid-twentieth century societies, set goals and benchmarks for effective public participation that precede modern constraints for the planning profession. Contemporary resources have since emerged from these foundational ideas to provide practical recommendations aligning robust citizen engagement practices with the dayto-day responsibilities of local officials.

Modern tenants of collaborative planning stress future-oriented thinking that is inclusive and transparent. Community growth is no longer regarded as a linear progression contingent on strong elected leadership or an innovative breakthrough. Instead, development is multidimensional and involves thorough consideration of how current decisions will affect future community members. The path from community input to implementation of equitable policies is complex, ongoing, and cyclical (Healy 2010).

Contemporary collaborative planning also measures quality of life based on the livability and sustainability for the many in a community, not only the committed few, namely "older, male, long-time residents, voters in local elections, and homeowners" (Levin Einstein, Palmer, and Glick 2018). Incorporating a wide range of perspectives is regarded as increasing the 
"intelligence of a policy," allowing local leaders to make well-informed decisions based on stakeholder experience and public knowledge (Healy 2010: 19).

The classic conceptual contributions to participatory planning of Friedmann and Arnstein are rooted in the $20^{\text {th }}$ century context and therefore miss the particular constraints faced by small cities in the 2020s. The tensions of fiscal austerity and amenity provision, the rapid demographic shifts, the unpredictability of economic growth in late capitalism, all disproportionately impact small cities, and cause the path to collaborative governance to be far from linear (Kading 2018). The challenge becomes to adapt the classical notions of participation to this context. 


\section{CHAPTER III: STUDYING THE MEANING-MAKING PROCESSES OF SMALL CITY LEADERS}

This study explores how municipal leaders reconcile conflicting obligations in their work. More specifically, I analyze how small city leaders pursue citizen engagement while managing bureaucratic expectations. For the purposes of this research goal I studied up, gathering insights about public participation from individuals who hold positional authority over their community's development. The experiences and testimonies gleaned from conversations with these organizational elites inform a discussion about the citizen engagement processes of small cities and how functionaries make sense of the structures that influence the priorities of their work.

\section{Interviews with Small City Leaders}

I conducted a total of ten semi-structured interviews with community leaders of a small city. These included both solo and group interviews with two city planners, five regional planners, two alder persons, a former city councilmember, an economic developer, the general manager of the community transit authority, and the director of the community's

environmental center. These individuals were purposefully chosen as a non-probability sample of prominent yet accessible leaders whose combined experiences and perspectives could inform on the citizen engagement processes of small city government.

I solicited interviews from my research participants through emailed invitations. Each interview occurred in the respondent's place of work and lasted between 30 and 90 minutes. Prior to each interview, respondents consented to the research aims and to having their responses recorded for transcribing purposes. To preserve the confidentiality of my respondents, I use pseudonyms to refer to the research participants and to obscure potentially 
identifying characteristics of the small city, henceforth referred to as Woodridge. I selected Woodridge based on its adherence to Jon Norman's (2013) criteria for small city designation. All of the leaders I interviewed were from this one case study whose attributes and government structure are representative of midwestern small cities.

Prompted by a semi-structured interview guide, the respondents answered a series of questions about their occupational role and responsibilities, the influence of groups both internal and external to their department, and their motivations and processes for engaging with citizens. A collection of probing and follow-up questions supplemented the semistructured interview guide, allowing for more open-ended responses intended to thicken the descriptions gathered by the data (Rubin and Rubin 2012).

Emulating George Mason University Associate Professor of Integrated Studies Dr.

Samuel Frye's (2017) case study on small city downtown revitalization, this study builds on the assumption that interview participants "[create] meaning through their experiences" and then "[negotiate] meaning overtime through interaction" with one another and the community. By studying the experiences and interactions of the Woodridge officials, I seek to identify the meaning-making processes of small city leaders in regards to public participation.

\section{Content Analysis of Planning Documents}

In addition to interviews with small city leaders, I conducted an informal content analysis of comprehensive plans and marketing materials for Woodridge to supplement the interviews. This analysis included two award-winning comprehensive plans that carry through 2035 and 2040, a 2024 consolidated plan, a 2021 action plan, and a ten-year master plan. These documents offer clues as to how the Woodridge leaders think and talk about public 
participation. They also provide a snapshot of citizen engagement processes and how the small city outlines its long-range priorities.

\section{Considerations for Interviewing Elites}

Research with municipal leaders, city planners, and economic developers requires specialized practices and considerations that are unique to studying up. Interviewing elites involves, per its definition, an asymmetrical interaction of power and privilege between the interviewer and interviewee (Empson 2018). This practice contrasts the studying down practice of many other social science inquiries where the researcher, due to their academic and professional credentials, can tend to hold more authority over the conversation. As a result, studying up is less frequent, but provides a rich perspective of social phenomenon by individuals who "wield significant influence in society" (Delaney 2007: 208).

Studying up requires first gaining access to social elites. This can involve navigating around a "gatekeeper," or an administrative individual who acts as an intermediary between the researcher and the desired respondent. In soliciting interviews for this study, I interacted with several secretaries and assistants who responded to the initial interview invitation and arranged a meeting time (Harvey 2010).

Interviewing elites necessitates tact in guiding the progression and direction of the conversation. Studying up implies a power dynamic where the researchers is not always assumed to have authority over the discussion. Social elites may feel inclined to deflect certain questions, give inauthentic or exaggerated responses, or backtrack on questions to provide justification for their decisions. To retain control of the conversation, researchers can host interviews in a neutral location, or flex cultural capital to reinforce their credibility (Hunter 
1995; Rice 2009). To build rapport with my respondents for this study, I highlighted my academic credentials, institutional affiliation, and mutual connections with the respondent. Organizational elites may not so easily solicit transparent, honest responses with the researcher. Seeking to represent their department in a positive light, several local leaders offered responses more along the lines of an organizational spokesperson than their candid perspective. Structuring the interviews with probing questions, transparent research aims, reaffirmed confidentiality, and a progression from basic to more advanced questions helped orientate the respondents towards an authentic conversation. (Delaney 2007; Hunter 1995; Morris 2009).

\section{Inductive Analytic Approach}

I analyzed the interview responses using meticulous rounds of coding to ensure flexible and reflective investigation of the data. This study pulls heavy guidance from the principles of inductive reasoning. As such, the guiding research questions were routinely revised according to themes that emerged organically from the data. This study began as an investigation into the circumstances that prompt interactions between local leaders and the public, the effectiveness of the engagement tools used, and small city leaders' perspectives about their outreach processes. Through careful coding of the interview responses, I developed more nuanced insights into the meaning-making processes of small city leaders and revised my research aims accordingly.

Following the principles of inductive analysis, I developed sensitizing concepts to ground my research based on themes I anticipated finding. First defined by the sociologist Herbert Blumer (1954), these concepts offer a "general sense of reference and guidance" to inductive 
research. Sensitizing concepts for this study included racial, socioeconomic or age-related inequalities, references to communication and dissemination methods, or mentions of structure or agency in the respondents' experiences. These concepts framed my initial research questions and guided early rounds of coding, sensitizing me to ideas that emerged during data collection and transcription analysis. Through consecutive rounds of coding new themes emerged from the data, built from the initial guiding concepts (Bowen 2006; Charmaz 2003). Meticulous coding is necessary to inductive research analysis. It is the process from which themes, inconsistencies, and new points of inquiry emerge, ultimately shaping the objectives of the study. Coding is largely suggestive, building off of sensitizing concepts and other terms in the data. This means that, if initial categorization is too shallow or misguided, it subsequently affects the findings of later analysis. However, the subjectivity of coding is also one of its core assets as the relative flexibility of the practice allows the research findings to emerge naturally out of the data, independent of preconceptions or hypotheses (Rubin and Rubin 2012).

I transcribed and then analyzed each of the interviews according to Joel Aberbach and Bert Rockman's (2002) manifest, latent, and global strategies for coding interviews with organizational elites. Manifest coding items begin by organizing answers based on question prompts. For example, responses to the interview question that asked respondents to describe their work were sorted based on the roles and responsibilities defined. Often more explicit, themes pulled from manifest coding are considered more reliable. Latent coding items seek to capture more latent meanings and themes. These included responses about how local leaders felt about their capacity to complete a certain initiative, expectations placed on them from 
superiors, or critiques from the public about policies they had control over. Third are global coding items that focus less on specific content or the meaning behind a response, and more on the structure by which the response is articulated. For example, how a leader breaks down their citizen engagement process into subsequent steps involving varied groups of individuals. All three of these coding levels were used to pull out major patterns from the interview data, capturing both the breadth and depth of the community leaders' responses.

\section{Limitations}

The methods and findings of this study are limited to the small city of Woodridge and its leadership. While offering an underrepresented perspective of small cities, the opportunities and capacity of the Woodridge leaders is not necessarily indicative of other small cities, both nationally and internationally. The growth and direction of Woodridge are the result of a growing downtown, family-friendly amenities, and the university among other assets. Given that small cities are not monolithic, not all small cities have these resources and, conversely, Woodridge may lack other small city attributes that would have generated citizen engagement differently.

For the purposes of this study the terms planner, functionary, and local leader are used interchangeably to refer to government employees serving in economic development, city and county planning, and government leadership capacities. This consolidation has implications for conclusions drawn about small city leadership as a broad concept. Depending on the priorities and resources of the department, citizen engagement approaches may vary considerably. For larger-scale studies, conducting a greater quantity of interviews and dividing the data based on the respondent's role might better inform how small cities operate at a department level. 


\section{Woodridge: A Profile}

This study takes place in Woodridge, a midwestern small city of 132,000 residents (US Bureau of the Census). I chose Woodridge to be the focal point of this research because it qualifies as a small city according to the size, proximity, and economic criteria of Jon Norman's (2013) small city designation. Woodridge adheres to Norman's size requirement of a total population between 100,000 and 200,000 residents. It is a dense, economic anchor for the surrounding rural region which differentiates it from similarly sized suburban or bedroom communities. Woodridge is the economic driver of its immediate regional area, serving as the "big city" for dozens of surrounding rural and small towns.

Settlers established the city of Woodridge in the mid-1800s. As a stop along a major rail line and the central hub for surrounding agricultural activity, Woodridge quickly grew in size. Shortly after the town's founding, community leaders also established the university with college students adding to the population. In the early 1900s, a finance company started out that would come to be the largest employer in the community. In the late 1900s, the city established an airport authority that led to the founding of a regional airport, increasing Woodridge's connectivity at a national scale.

As is common of other small cities, the local economy of Woodridge is dependent on a handful of major employers. These include the city's educational institutions: the university, community college, and school districts, and its healthcare facilities. In addition to these anchor institutions, Woodridge houses corporate headquarters for a pair of finance companies who together are the top employer for the city. Tax revenues from these businesses and resident 
homeowners have contributed to the small city's budget which funds municipal salaries, intergovernmental agencies including police and fire departments, and capital fund projects.

Demographically, Woodridge is predominantly white, college-educated, and middle class, with known pockets of low-income and people of color scattered towards the edge of the small city. The population towards the center of Woodridge is relatively young given its proximity to the university. The schoolyear of the university also impacts other aspects of Woodridge including the city's rental housing market, community and cultural events, and minimum wage and entry level jobs.

The leaders of Woodridge, whose offices are housed downtown, mirror the majority demographics of the small city. Of the leaders I interviewed, most were white and welleducated, with a relatively even split between men and women. These individuals filter into Woodridge's government structure with the mayor and city council at the top, followed by other governmental departments with a small team of staff such as planning and zoning, economic development, and parks and recreation. Overlapping with these core governing bodies are various boards, commissions, and other community development agencies including the transportation authority and sustainability center.

In its long history, Woodridge has experienced interdepartmental and community-wide conflict. Decades of population and economic growth have provoked disagreements between community leaders, business interests, social institutions, and the public. The city and university long held a strictly town-gown relationship marked by small disputes over student housing and zoning requirements, though this has improved in recent years as the two institutions formed what both refer to as a flourishing partnership. Downtown redevelopment has also been a 
point of contention between local leaders and the public. Disagreements about the scale of proposed development and the handling of historic structures have carried animosity over into public forums and the local election. Despite these growing pains, Woodridge expects to continue steadily developing, drawing in new businesses and attracting residents with its improved amenities. 


\section{CHAPTER IV: ASSESSING THE OCCUPATIONAL EXPECTATIONS}

\section{AND CONSTRAINTS OF THE WOODRIDGE LEADERS}

Local political and economic leaders in Woodridge view their role as both fulfilling and restrictive. They derive satisfaction from roles that they view as "rewarding" and from acting on behalf of the public good. Yet, at the same time, they recognize that they operate under a set of structural constraints that limit what they can accomplish. While local leadership laments those constraints, they do not seek to challenge them. Rather, they tend to view these structural limitations as inherent and inevitable.

The interviews indicate that precedent and policy initiate many of the interactions local government officials have with their constituents. Functionaries are preoccupied with banal procedures and political obligations that tend not to incentivize nor reward community outreach. As a result, many adhere to state mandates and municipal code that dictate the minimum requirements for outreach and collection methods. Functionaries prioritize surveys, public hearings, or focus groups with stakeholders to gather input from the public because of their efficiency and connectivity with the community. However, they recognize that these engagement mediums can leave out underrepresented populations including low-income residents, non-English speakers, college-aged Millennials, and homebound elderly.

Stakeholders are a reoccurring third party who underlay citizen engagement processes and hold significant influence over the interactions between local leaders and their constituents. "Stakeholders" is a catch-all term for donors, local businesses, developers, and community organizations that act as intermediaries, facilitating interactions between planners and the public or offering perspective on community needs. Considering the average small city 
houses a hundred-thousand residents, it is beyond the capacity of local government departments to collect feedback from everyone. As a result, functionaries use their stakeholders as a substitute for direct constituent feedback.

The planners of Woodridge value public outreach as a fulfilling, foundational part of local government work. However, they frame citizen engagement as a secondary task rather than a driving priority. Under ideal conditions of communicative planning, local officials and the public share the responsibility of community growth. True collaborative planning requires consistent, two-way channels of communication with progress based on consensus. Instead, bureaucratic forms, approval processes, and meetings dominate local government work, pulling planners' time and attention away from citizen engagement.

Local leaders face a set of structural constraints that narrow the scope of the possible within their work. Specifically, there are many limitations to planners' ability to obtain wide and substantive community input on short and long-term planning processes. These constraints are a result of occupational structures that stretch planners thin with competing demands. In the following sections, I identify the organizational, methodological, political, and class expectations that set the agenda of local government work. I then outline how aspects of these structures constrain planners' day-to-day work, thereby inhibiting citizen engagement from being an inclusive, integrated part of community development.

\section{Leaders as the Swiss Army Knife of the Community}

I'm in charge of the orderly development of the town of Woodridge. So I'm in charge of any new construction, major remodeling, to make sure it's in compliance with the zoning code and the comprehensive plan. But I also do historic preservation, downtown 
planning stuff. I do bicycle, pedestrian planning. Kind of a lot of sustainability things, which are kind of vaguely defined. A lot of special event type stuff, special projects I end up doing because planners are often the swiss army knife of the staff, you kinda just know enough to do things.

In the quotation above, a small city planner characterizes her job as being "the Swiss army knife of the staff" and her skill set as knowing just enough to be assigned a wide variety of responsibilities. This notion, that planners are generalists rather than specialists, is so widespread within small city leadership that planners themselves internalize it, and it serves to spread planning staff too thin and divert their energies away from substantive participatory planning. This section outlines the structural constraints that result from this Swiss army knife phenomenon.

Serving as the city's jack-of-all-trades does not leave planners much bandwidth for planning itself, much less for soliciting and incorporating citizen input into planning processes, which, to perform substantively and inclusively is a labor and time-intensive process. Planners adapt to this heightened workload by either trimming off tasks, performing only what is mandatory, or over-extending themselves.

The small city size of Woodridge adds to the ambiguous delegation of responsibilities among municipal departments and planning staff. The community has multiple planning departments and community development institutions, but there is little cross-department collaboration. Instead, as a transportation planner explains, projects are funneled into a vertical hierarchy where all of the departments report up to city authorities and out to business 
interests and developers. Citizens are also burdened by constant asks for survey and focus group data from the uncoordinated departments.

When planners do undertake planning directly, they distinguish between short and longterm planning. Short-term planning, which encompasses most of their work, includes banal tasks like processing paperwork, reviewing ordinances, and responding to funders. All largely reactive, these daily responsibilities are heavily circumscribed, guided by established step-bystep procedures, zoning codes, and building policies. One planner stresses the immense time commitment of short-term tasks:

The things that take up my daily life are things like planning commission items like the new Jiffy Lube that's going to be built and plotting the property and I have to look at the building plans. That kind of stuff just takes up quite a bit of time.

Meanwhile, long-range planning is proactive, comprised of comprehensive reports that lay out a community's priorities and direction for the upcoming years or decades. These reports function as a visionary backbone for local leaders' work, or a "lens to view projects," as one developer describes it.

Citizen input is regarded as "foundational" to long-range planning but is rarely collected and mobilized substantively. Planners overwhelmingly employ the rhetoric of citizen participation. One interviewee, for example, stated, "community buy-in and input is fundamental to doing any plan, especially a good plan. If you want something that people are going to support, then they should be involved in the process." In practice, however, feedback is typically only collected during early phases, rather than throughout the long-range planning process, as one planner explains: 
We interact with the community more during the outreach phase. Since we are very much long-range planning focused, we try to get as many people engaged in the longrange plans. We don't interact with members of the community on a daily basis. Most of our interaction is only during the early planning phases, but we don't have any regulatory authority so we do not interact with them daily.

Local leaders, particularly those occupying non-elected positions, find that a lack of "regulatory authority" severely limits their ability to collect robust public feedback. Instead, the duration and depth of small city "outreach phases" depends on endorsement from funders or local political momentum. Larger projects with more lenient timelines can launch extensive survey campaigns that make use of community newsletters, social media, and existing city events to market the outreach opportunities. Reports with shorter implementation periods, such as an annual Community Development Block Grant (CDBG) Action Plan, generate fewer responses and lead planning departments to subsequently rely on stakeholder input to supplement public opinion.

\section{The Standard Operating Procedures of Engagement}

Small city local leaders employ methods of engagement that maximize efficiencies and boost the quantity of responses. Functionaries tend to use tried-and-true methods of engagement, including surveys, focus groups, and public hearings. These methods, referred to as "just standard operating procedures" by one elected official due to their routine use, are preferred by local leaders because of their convenience. However, these tools are more susceptible to tokenistic engagement that treats outreach as more a symbolic gesture than an opportunity for cooperative community development with the public. 
Functionaries employ the trio of engagement methods to garner the largest quantity of public feedback while maximizing their efficiency. Their preference is driven by necessity, as planners have to weigh the comprehensiveness of their methods against municipal budgetary constraints. Functionaries value the utility of varied engagement methods but are restricted to those that they have both the resources and capacity to pursue. They perceive the public as holding similar priorities:

People are going to do the things that are in their best interest but that require the least - not the least amount of effort - but are in their best interest and can be done most efficiently. So if you make it really challenging like having a lot of obstacles and barriers, people are less likely to attend [engagement opportunities]. So any time you reduce those barriers, you kind of get better attendance.

As technocrats, local leaders seek to maximize efficiencies in their work. In the realm of generating public feedback, this has come to mean "reducing the barriers" for the public to engage. As the above quote articulates, functionaries perceive the public as motivated by civic opportunities that are "in their best interest," or those with clear personal relevance and convenience. Tapping into those perceived expectations, local leaders approach engagement in ways that they have determined are most accessible to the public.

Surveys offer local leaders the versatility of quickly collecting public opinion about a project and then efficiently disseminating the results of that input. Paper surveys can be easily distributed in person at local events or left at highly trafficked locations like libraries or community centers. Government departments can also share survey opportunities on their website or social media pages. Unlike lengthy interview, public comment or focus group 
responses, survey data produce digestible statistics and graphics for convenient sharing with the public and stakeholders.

Local leaders favor personal, conversational methods of engagement but, in practice, draw the most utility from quantitative and closed-ended prompts. For example, one elected official stressed the value of face-to-face conversations in encouraging "honest and meaningful dialogue" with residents of his ward. Another planner made a point of separating her methods of public outreach from other functionaries who solely collect surveys and then "call it community engagement." Despite this stigma against surveys, they were the most routine outreach tool mentioned in the Woodridge interviews.

This prioritization of quantifiable feedback is also reflected in how Woodridge comprehensive plans and city brochures disseminated public comments. Survey data were showcased as statistics that highlight public opinion, demographics, and economic growth. Interview, focus group, and public comment data were condensed into visionary boards or word clouds of commonly used terms. Short-answer responses were included as selective quotes or condensed into community priority areas. For example, multiple long-range plans list the city's "small town feel with big city amenities" as a shared value among Woodridge citizens.

Local leaders rely on numerical data to succinctly market the city as economically and socially well-off. They collect macrolevel data about jobs, retail, and schools, or the "hard aspects" according to one regional planner, that can be showcased in brochures to substantiate claims that the small city is "vibrant" and "thriving." "Soft aspects," or more descriptive community qualities, are regarded as too prosaic to be included in official city publications. One 
city planner explained this as the difference between her views about the community as a private citizen and what she is expected to report on as a local government worker:

If I'm just describing Woodridge to people I just think of it - because this is not going to be some public document, this isn't a marketing piece - l'd like to tell people it's just a nice, easy place. And at my stage in life I value nice and easy very highly. It's been a great place to raise my kids. It's safe, people are generally pleasant, there's generally not a lot of traffic, I can generally get on my bike where I want to go as can my kids. The trail is amazing. It's just an extremely nice place to live, and I think that's actually...that can be celebrated. I mean, it's nothing anyone would ever market or use as a marketing piece but, I don't know, I'm just glad people are generally nice here.

Technocratic efficiencies diminish the descriptive quality of public feedback. As stressed in the quote above, official city documents dilute public comments, filtering out subjective qualities that make the city "nice" in favor of quick statistics. This overreliance on quantitative, closed-ended methods of engagement severely limits the utility and applicability of public comments. In consequence, local government conducts systematic processes of engaging with the public, but the outcomes of those efforts are not necessarily representative of how citizens intuitively think about the city.

Local leaders value citizen engagement but employ limited methods of collecting and using the information. This superficial participation qualifies as tokenism, a stage marked by perfunctory efforts to gather and share citizen input (Arnstein 1969). This non-representative approach pulls from a selection-biased segment of the population that is used to represent the 
whole. Local leaders, laden with restrictive workloads, fall back on these sorts of symbolic gestures as they comply with mandated engagement requirements.

\section{Appeasing Stakeholders}

Beyond the limitations of planners' structural positions as local governments' Swiss army knife, external stakeholder groups exercise outsized influence in the planning process, further limiting substantive participation. To increase efficiency and receive sufficient input, planners rely primarily on feedback from stakeholders, such as community organizations or local businesses, rather than soliciting input from the general public. Planners' dependence on stakeholder input diminishes the merit of public comments. In this section I turn to the role of stakeholder groups, including funders, in delimiting the range of citizen participation in city planning, taking the place of substantive, broad-based community participation.

Small city functionaries and officials are principally beholden to stakeholders or clients, many of whom are funders but others of which are businesses or non-profit organizations with outsized influence over planning decisions. The term stakeholder is used liberally by community leaders as shorthand for formal organizations with political capital that place demands on city leaders. Stakeholder groups themselves and the political capital they exert become structural forces that shunt planning into certain directions and away from others.

Local community leaders consistently treat "stakeholder engagement" as interchangeable with general "public engagement," but the two are not synonymous. Stakeholders engage with planners from positions of authority, offering connections and expertise beyond those of the average citizen. "Stakeholders" as a term serves a discursive 
purpose for city leaders, serving as a stand-in for citizenry that can exonerate planners from having to communicate directly with citizens.

While local leaders value public input, they are structurally incentivized to prioritize stakeholder feedback because they are beholden to stakeholders-as-clients. Therefore, they learn to see stakeholder feedback as more relevant and salient than direct citizen participation. One planner explains:

I'm not gonna sit here and say that we reach everybody, but to people who are seeking this information we try to be accessible. A big part of our role is to engage our stakeholders. We don't deal with the everyday public, we deal with our stakeholders, so our biggest clients are municipalities, non-profit organizations [and] policy-makers. Stakeholders also have greater access to planners because they both speak the language of state-mandated municipal codes. These mandates form the scaffolding of local governing bodies, regulating planning tasks that range from land use policies to roadside signage. The codes, while dense and unfamiliar to the public, are guidelines that streamline and simplify the work of planners and their stakeholders.

Typically if [projects] are meeting code it's gonna move forward because there would be no mechanism to stop you, you know? They're doing it as of right. The code is there, they're meeting the code, boom. And usually people aren't trying to do something that generally doesn't meet code. They kind of already know before they buy the land, they run things through us. So, you know, there's a process for it. Planners and municipal functionaries often refer to "clients" or "customers" as interchangeable with stakeholder groups. Both terms lay bare the market-oriented ideologies 
of local government officials. One planner, for example, when asked about soliciting participation from the marginalized populations that her community development block grants are explicitly intended to serve, conveys that she would instead consult non-profit organizations that work with those populations. Only when these stakeholders were "swamped" would she survey her clients directly. Similarly, planners at a metropolitan planning organization (MPO), despite being publicly funded, are overwhelmingly focused on appeasing their "clients" as a funding strategy. MPOs are federally mandated, and ostensibly act on behalf of the public, but in practice they are caught in a funding trap, chasing grants and contracts from "stakeholders" and "clients" with special interests.

Funders as a stakeholder group hold significant sway over the progress and direction of local development. State and federal grant funds and community businesses set restrictive parameters for how critical planning funds can be used. Being beholden to "soft" money represents challenges and frustrations for small city planners, as these funds often come with contingencies that can stifle creativity. Planners have to strike a "very delicate balance" between routine tasks expected from their funders and the innovative and more social justiceoriented projects they aspire to pursue because they believe it will improve the community. Local officials aim to offer out-of-the-box solutions, but a lack of resources instead confines them to a "strictly defined box."

The constraints of funding and stakeholder-courting create an environment where public engagement is conditional and curated. Planners do not have open, consistent, and impartial channels of communication with the public, rather; stakeholder input is used as a proxy for public opinion. These constraints take multiple distinct forms. First, the structure of 
funding and incentives means that more innovative, future-oriented, and social justice-focused initiatives are less likely to find purchase than economic development-oriented projects. Second, stakeholders shape the character of these projects with a focus on the routine and procedural. Third, the mere use of the terms "stakeholder" and "client" signifies the market ideology of local government.

\section{Reaching the Hard to Reach}

The tools and techniques small city planners employ to collect input from the citizenry work to undercount historically underserved groups. This set of limitations dovetails with the bureaucratic and funding constraints discussed in the previous two sections to further limit substantive, broad-based participation in small city planning. These "hard-to-reach" populations as planners characterize them, include, as one participant put it, "college students, the elderly, people that don't speak English, minorities, [and] low-income" residents. Local leaders are cognizant of their failures to reach these demographics but continue to use engagement tools and techniques that are inaccessible or unfamiliar to these groups.

The typical timing, location and means of advertising public hearings and focus groups work against their accessibility to hard-to-reach populations. Low-income residents, second and third-shift employees, and citizens with children have work and family obligations that conflict with evening engagement opportunities. Elderly residents may follow local politics but lack transportation to municipal meetings, while college students may have the means to attend public forums but are out of the loop when hearing notices are posted in local newspapers. One planner explains the logistical difficulties of getting underserved groups to in-person events: 
Ideally we would be reaching as many of those people as possible which is why we're going to the types of events that we are. But sometimes they're the hardest population to reach because their lives are already complicated. You know what I mean? Cause you're asking these people who might work weird shifts, maybe working more than one job, [or] don't have access. Everything in their lives is more complicated right? Socioeconomic and racial disparities between planners and marginalized constituents also constrain participation because planners often look to their own social circles for feedback. One local planner described her unsuccessful effort to solicit participation from low income parents thusly:

I tried to do...well maybe if we provided child care, but then you're like so I'm going to reach out to a low-income person, well generally speaking the people in your social circles are generally somewhere around your same socio-economic status, it just happens. I don't have like, well I've got this perfect acquaintance who's like a great single mom, low-income. Nobody just like springs to mind. I mean we ask everybody we know, like, do you know anybody who fits this? And then it's like you might, but then it's too hard to get people involved.

In this quotation the speaker begins by narrating an effort to provide childcare in order to draw in working single parents to participate, in this case on a transit board. However, the speaker quickly pivots to conceding that board representation is comprised of her "acquaintances" and that her "social circle" is limited by strong homophilic composition. The quotation also conveys a perfunctory quality to her efforts. Phrases like "it just happens" and 
"nobody springs to mind" convey that the speaker considers public participation more of an afterthought than a central activity.

This "social circle" effect is unique to small cities. Planners in large cities have procedures in place and resources behind them to cast a wide net. Small city planners, however, because they circulate socially among progressive civic-minded elites, and because these are smaller and denser networks in small cities, draw overwhelmingly from these groups for input. Further, the breadth of their roles, owing to the Swiss army knife phenomenon discussed above, leaves little "bandwidth" for soliciting deep and representative participation, and drawing from one's social circle is the most expedient way of collecting obligatory community input.

Planners are aware of the bias built into the community participation process, and, in some cases they attempt to address these limitations. However, they do so in palliative, technocratic and incremental ways. For example, some planners have had their surveys translated into the primary languages of immigrant populations. Others have made efforts to bring surveys out to community events. The city also included rhetoric around reaching the "hard to reach" in a 2040 comprehensive plan, asking, "how varied priorities expressed by different demographic groups can be accommodated," and "how inclusive can [town plans] be in terms of age, income, race and ethnicity?" While acknowledging their omission from civic and political participation, posing these rhetorical questions in technical documents does not challenge the structures at work.

The University of Woodridge is a critical economic asset for the city and surrounding region, as higher education institutions tend to be for small cities, but as planners have come to 
treat the university as a stakeholder, the interests of institutional leadership has come to act as a proxy for meaningful conversation with students, faculty, and staff. Despite making up nearly a quarter of Woodridge's population, college-aged young adults remain a population out of reach. Communities recognize the transitory status of college students and are resultingly hesitant to commit resources and attention to a population who they see cycling out of the community in a few years. Considering the individual needs of college students is seen as taking a risk to already limited municipal funds and resources:

I think for a lot of college students I hear a lot about creating new internships, new opportunities, things that are really catered to college students, but that's part of the natural flow of people growing and changing and their money going in different directions...And there's always the question of, you know, if we take some steps that are gonna try to keep some folks here, will people actually stay here? And are we out that money, or are we out that investment, and there's nobody here? There's always a risk, you know, and again I really like to listen and try to understand the bigger picture of issues. There's not just one right way to deal with things.

When local leaders reach out for community input, the "easiest-to-reach" populations, namely white, middle-aged, well-educated and middle class citizens, consume an outsized portion of planners' time and attention. Within this group are a portion of individuals whose heavy-handed, unsubstantiated claims sour planners on public participation altogether. In the polarized and hostile political climate of the contemporary midwestern United States, efforts to collect public comments online and at town halls are monopolized by an "emboldened" minority that seems "pretty darn anti-government." These citizens spread misinformation and 
render public comment spaces toxic and uninviting for others, joining a rise in opposition against neighborhood development colloquially referred to as NIMBY, or not in my back yard. These encounters raise local officials' hackles and put them on the defensive regarding all community feedback.

I mean I think one of the main challenges is - at least for me right now - it's how do you deal with the presence of political enemies or political opponents and still create a space that's inviting and welcoming for your supporters? Or for even just your average resident that isn't taking a side but wants to follow you to ask a question? If you look at my social media page, it's a mess with comments. Really, really negative comments. In the above quote, an alderperson explains the challenge of maintaining and regulating a social media page. The sites allow functionaries to reach a broader audience, but social media has also opened local governmental departments up to harsh scrutiny and criticism. The authority that planners hold at a hearing or in a face-to-face conversation is less commanding against the relative anonymity of public comments online.

Municipal functionaries employ tools and approaches to collecting community input that exclude so-called hard-to-reach demographics - the elderly, the poor, racial and ethnic minorities, immigrant groups and college students. Instead a selection-bias toward those in local leaders' social circles is baked in to the process, and vitriol from far right constituents often "blows up" efforts to collect citizen input. Compared to findings of other qualitative studies on citizen engagement, small city leaders are not the only functionaries that have to balance structural constraints with professional autonomy, but the mid-range size of small city 
populations and government departments add additional challenges for planners including an overreliance on stakeholders and contacts within their own social circles. 
CHAPTER V: SUMMARY

\section{A Discussion of How Small City Leaders Make Sense of Constraints in their Work}

This study set out to understand how small city government leaders make sense of their occupational obligations to represent the public while managing the bureaucracy of their work. My findings indicate that small city leaders struggle to manage these competing expectations, and this has implications for citizen engagement as structural demands limit functionaries' capacity and motivation for outreach efforts. Local leaders make sense of these constraints by accepting them as inherent to their work. They respond with resignation, describing the challenges as routine and at times necessary to the department's functioning.

Local government as an institution dictates the priorities and capacity of its employees. These structural constraints have implications for the methods, frequency, and quality of functionary-generated public input. Collaborative planning theory argues that robust public participation depends on citizens holding decision-making authority over their community's development. Instead, Woodridge citizen engagement is heavily influenced by the budget, capacity, and priorities of its local governing officials. The local leaders are the adherents and enforcers of bureaucracy, striving for expediency, and this approach carries over into how they seek to represent the entire community's interests.

Several of these constraints to public participation are complicated by Woodridge's status as a small city. The department size of small city government necessitates that functionaries take on a wide range of responsibilities that limit their ability to dedicate themselves more exclusively to citizen outreach processes. The autonomy of functionaries is at the whim of funders' priorities due to the rigid budgets of small cities. In Woodridge, budget 
cuts forced several planners to abandon innovative development projects. Faced with budgetary and capacity limitations, small city functionaries rely on stakeholders to generate sufficient feedback. Faced with low public participation rates, the Woodridge leaders depended on their own personal and professional connections to extend their social reach, adding to a cycle that tended to exclude members of underrepresented populations.

Collaborative planning is contingent on local leaders entrusting leadership roles and decision-making authority to the public. High-level public participation requires that the public can negotiate the rules of engagement, regularly taking the lead of outreach efforts and being held accountable for their decisions. Small city leadership can take steps to encourage more inclusive, transparent engagement by updating their outreach methods and prioritizing input and leadership from members of underrepresented groups. Were feedback opportunities more accessible and the collected input more digestible, citizen engagement could be an ongoing, reflective conversation rather than a conditional step in a process. In this section, I outline opportunities for improvement conducive to small cities that would improve current engagement processes.

\section{Recommendations for Improving Small City Government Practices}

Addressing the occupational constraints of the Woodridge leaders requires substantial updates to their local governing procedures. These include specific improvements to amend the organizational, methodological, political, and social expectations of their work. Implementing the following recommendations would better enable small city leaders to pursue public participation that is robust, inclusive, and citizen-driven. 
Small cities can increase the organizational capacity of its government workers by improving how responsibilities are delegated within and across departments. To free up the broadband of specialized functionaries, small cities can restructure delegation to lessen bureaucratic task loads. Departments can also hire on bureaucratic staff whose specific purpose is to manage more generalist responsibilities. Updating the organizational structure of small city government departments could free up planners to focus on facilitating public participation, thereby treating them like experts that they are.

Small city leader should also make citizens, especially underrepresented individuals, a priority, and minimize their dependence on stakeholders as a proxy for public opinion. Stakeholders offer small city leaders the opportunity to get a facsimile of public opinion without gathering input from every individual in the communities. The leaders often see stakeholder input as expedient and, at times, the only viable option due to a lack of resources. Increased funding and capacity could enable small city leaders to use personalized methods of outreach to increase accessibility for underrepresented community members thereby decreasing their dependence on stakeholder feedback.

Modernizing public engagement tools, processes, and information sharing would improve the limited reach of traditional outreach procedures. Citizen outreach efforts should balance collection of thick, descriptive qualitative feedback alongside survey-derived numerical data. Surveys offer logistical ease and affordability, but planners recognize that "people get tired of filling [them] out." Surveys do not adequately capture the nuances of citizen experiences and opinions; rather, planners have found that the public, including several hard- 
to-reach populations, are more responsive to a conversation held in person in an informal setting.

Planners should also consider how feedback is evaluated and information is disseminated to the public. Community forums and public hearings capture qualitative input, but that data is null if poorly integrated into long-range plans and policies. For example, Woodridge successfully markets the statistics gathered through surveys and census data, but forum comments are far less circulated. One regional planner articulates this point using the example of a new bus stop:

Sometimes it's not just about data. You know, data might only show that there are five people using [a bus stop], but if these are five people who really need to be using it, should we just look at data? You know, where does empathy play into all of this, right? Because at the end of the day we are here to serve people, so as much as we talk about data, we also really, really - if you look at any of our documents we put the human context in.

As highlighted in the above quote, planners should be cautious to consider the effectiveness of what Arnstein refers to as "window dressing rituals" that evaluate progress by the number of pamphlets distributed, surveys collected, or conversations had rather than the rigor of the methods and quality of the content. Planners can amend this by being more intentional with their citizen outreach, ensuring that engagement is not measured by the quantity of participation, but by the level of empowerment of citizens to be involved in and feel that they are represented by their local leaders. 
Social media is a low-cost but high maintenance communication tool. Local leaders recognize that an online presence gives them greater access to the public and, conversely, allows community residents the convenience of engaging with their local government officials. However, planning departments have not widely adopted social media because of capacity limitations, barriers of access for marginalized populations, and past challenges with generating feedback using the platform. Functionaries would benefit from trainings on how to leverage social media to reach the greatest number of community members while mitigating the onus on functionaries' time.

Amid ongoing changes to the processes and leadership of small city government, municipal leaders will need to consider how to modernize their methods and organizational structure to encourage diverse, inclusive engagement. Planning continues to modernize with emerging technologies and fresh perspectives, but if the ultimate goal is to empower citizens beyond tokenistic planning, local leaders need to also integrate changes into existing planning processes. Structural constraints limit planners' bandwidth for citizen engagement, but there are steps that they can take to encourage more equitable community planning.

\section{Conclusion: The Future of Small City Governance}

This study sought to capture the perspectives and experiences of local government employees to inform dynamics of participation between leaders and their constituents. Interviews with small city local leaders and a cursory content analysis of comprehensive plans indicate that organizational, methodological, political, and social expectations impede inclusive, collaborative citizen engagement. Planners, as generalists, have limited bandwidth and creative freedom to interact with community members. Instead of challenging these occupational 
constraints, the Woodridge planners accepted their role as part of a much larger, immutable political structure.

The age of uncertainty brought on by the coronavirus has made apparent the importance of functionaries to provide guidance for communities. The virus completely altered how people gather, highlighting the utility of online platforms and the need for modernized forms of outreach. It also shed new light on existing disparities for individuals of marginalized groups, prompting planners to consider what sort of normal they want to return to in terms of access and inclusivity.

As the country looks to recovering from the virus, realtors speculate whether small and mid-sized cities will attract residents of big cities who are seeking open green spaces and affordable housing from which to telework. Small cities will continue to dominate the American landscape as once-industrious cities shrink or small-town communities grow, prompting an urgent need for information about the life and development of these uniquely sized communities. This study offers a missing qualitative perspective on the governmental processes of small cities from the perspective of city planners, community developers, and municipal leaders. The findings lend support to the argument that small cities' diversifying populations and mid-range size provide encouraging conditions for innovative, participatory community engagement.

The work of local political leaders, economic developers, and planners will continue to shape small cities. As was aptly stated by a Woodridge planner: "local government's a pretty big presence in your life even if you're not paying attention to it." It will be the task of functionaries to modernize their engagement processes to be accessible to a wider population and to market 
those opportunities so that more residents are "paying attention." Likewise, small cities must consider the capacity and interests of its civil servants. Under current structures, the Woodridge functionaries are inundated with obligations that put robust, inclusive citizen engagement out of reach. If small city municipalities aspire to lead collaborative planning efforts, significant changes are needed in the methods and representation and of public participation processes. 


\section{WORKS CITED}

Aberbach, Joel D. and Bert A. Rockman. 2002. "Conducting and Coding Elite Interviews." Political Science and Politics 35(4): 673-676.

Arnstein, Sherry. 1969/2019. "A Ladder of Citizen Participation." Journal of the American Planning Association 35(4): 216-224.

Baker, Bill. 2007. Destination Branding for Small Cities, Regions and Downtowns: The Essentials for Successful Place Branding. Portland: Creative Leap Books.

Bell, David and Mark Jayne. 2009. "Small Cities? Towards a Research Agenda." International Journal of Urban and Regional Research 33(3): 683-699.

Bias, Thomas K., Kevin M. Leyden and Jeremy Zimmerman. 2015. “Exploring Policy-Maker Perceptions of Small City Downtowns in the USA." Planning, Practice \& Research 30(5): 497-513.

Blumer, Herbert. 1954. "What is Wrong With Social Theory?" American Sociological Review 18: 3-10.

Bowen, Glenn A. 2006. "Grounded Theory and Sensitizing Concepts." International Journal of Qualitative Methods 5(3): 1-9.

Brennan, Christiana, Darrene, Hackler, and Christopher Hoene. 2005. “Demographic Change in Small Cities, 1990 to 2000." Urban Affairs Review 40(3): 342-361.

Buck, Roy C and Robert A Rath. 1970 "Planning as Institutional Innovation in the Smaller City." Journal of the American Institute of Planners 36(1): 59-64. 
Buenker, John D., and Theodore Mesmer. 2003. "A Separate Universe? An Exploratory Effort at Defining the Small City." Indiana Magazine of History 99(4): 331-352.

Charmaz, Kathy. 2014. Constructing Grounded Theory. 2nd ed. London: Sage Publications LTD. Collins, Kevin and Ray Ison. 2009. “Dare We Jump Off Arnstein's Ladder? Social Learning as a New Policy Paradigm." Environmental Policy and Governance 19(6): 358-373.

Delaney, Kevin J. 2007. “Methodological Dilemmas and Opportunities in Interviewing Organizational Elites." Sociological Compass 1(1): 208-221.

Empson, Laura. 2018. "Elite Interviewing in Professional Organizations." Journals of Professions and Organizations 5(1): 58-69.

Erickcek, George, and Hannah McKinney. 2004. "'Small Cities Blues': Looking for Growth Factors in Small and Medium-Sized Cities." Economic Development Quarterly 20(3): 232258.

Forstie, Clare. 2019. "Theory Making from the Middle: Researching LGBTQ Communities in Small Cities." City \& Community 19(1): 153-168.

Friedman, John, Robert Nisbet and Herbert J Gans. 2007. "The Public Interest and Community Participation: Toward a Reconstruction of Public Policy." Journal of the American Institute of Planners 39(1): 2-12.

Friedman, John. 2011. Insurgencies: Essays in Planning Theory. Abingdon: Routledge.

Frye, Samuel L. 2017. “Revitalizing the Forgotten Heart of a Small City: An Exploratory Case Study of Competing Perceptions, Experiences, and Interests in Downtown Development" Dissertation. Indiana University of Pennsylvania. 
Garrett-Petts, Will F., ed. 2005. The Small Cities Book: On the Cultural Future of Small Cities. Vancouver: New Star Books.

Green, Gary P. 2007. Workforce Development Networks in Rural Areas: Building the High Road. Northampton: Edward Elgar Publishing, Inc.

Griffith, Bryan, and Jessica M Vaughan. 2020. "Maps: Sanctuary Cities, Counties, and States." Center for Immigration Studies.

Habermas, Jürgen. 1981. The Theory of Communicative Action. Boston: Beacon Press. Harvey, William S. 2010. "Methodological Approaches for Interviewing Elites." Geography Compass 4(3): 193-205.

Healey, Patsy. 2006. Collaborative Planning: Shaping Places in Fragmented Societies. 2nd ed. New York: Palgrave MacMillan.

Healey, Patsy. 2010. Making Better Places: The Planning Project in the Twenty-First Century. London: Red Globe Press.

Henderson, Tim. 2017. “Millennials to Small Cities: Ready or Not, Here We Come." Pew Research Center.

Hunter, Albert. 1995. “Local Knowledge and Local Power: Notes on the Ethnography of Local Community Elites." Pp. 151-170 in Studying Elites Using Qualitative Methods, edited by R. Hertz and J. B. Imber. Thousand Oaks: Sage Publications, Inc.

Innes, Judith E. 1995. “Planning Theory's Emerging Paradigm: Communicative Action and Interactive Practice." Journal of Planning Education and Research 14(3): 183.

Kading, Terry, ed. 2018. No Straight Lines: Local Leadership and the Path from Government to Governance in Small Cities. Calgary: University of Calgary Press. 
Lam, Debra, and John Wagner Givens. 2018. "Small and Smart: Why and How Smart City Solutions Can and Should be Adapted to the Unique Needs of Smaller Cities." New Global Studies 12(1): 21-36.

Levine Einstein, Katherine, Maxwell Palmer, and David Glick. 2018. "Who Participates in Local Government? Evidence from Meeting Minutes." Perspectives on Politics: 1-42.

Mattson, Gary A. 1994. "Retrenchment and Fiscal Policy Planning: The Political Culture of Small Southern Towns." Public Productivity \& Management Review 17(3): 265-279.

Mattson, Greggor. 2019. "Small-City Gay Bars, Big-City Urbanism." City \& Community 19(1): 76-97.

Morris, Zoe S. 2009. "The Truth about Interviewing Elites." Politics 29(3): 209-217.

Norman, Jon R. 2013. Small Cities USA: Growth, Diversity, and Inequality. New Brunswick: Rutgers University Press.

Ofori-Amoah, Benjamin, ed. 2007. Beyond the Metropolis: Urban Geography as if Small Cities Mattered. Lanham, MD: University Press of America, Inc.

Adams, John S., and Barbara J. VanDrasek. 2007. “Urbanization of the Midwestern Countryside: The Case of Minnesota's Small Cities. Pp. (42-69) in Beyond the Metropolis: Urban Geography as if Small Cities Mattered, edited by B. OforiAmoah. Lanham, MD: University Press of America, Inc.

Bell, Thomas L., and Margaret M. Gripshover. 2007. "The Urban Corona Effect and Retail Change in Small Cities: The Case of Central lowa. Pp. 161-185 in Beyond the Metropolis: Urban Geography as if Small Cities Mattered, edited by B. OforiAmoah. Lanham, MD: University Press of America, Inc. 
Irion, Thomas. 2007. "Public Transportation in Small Cities: The Case of Marysville and Yuba City, California." Pp. (293-307) in Beyond the Metropolis: Urban Geography as if Small Cities Mattered, edited by B. Ofori-Amoah. Lanham, MD: University Press of America, Inc.

Ocejo, Richard E., Ervin B. Kosta, and Alexis Mann. 2019. “Center Small Cities for Urban Sociology in the 21st Century." City \& Community 19(1): 3-15.

Paradis, Thomas W. 2000. “Conceptualizing Small Towns as Urban Places: The Process of Downtown Redevelopment in Galena, Illinois." Urban Geography 21(1): 61-82.

Pitt, Damian and Ellen Basset. 2013. “Collaborative Planning for Clean Energy Initiatives in Small to Mid-Sized Cities." American Planning Association 79(4): 280-294.

Nevarez, Leonard, and Joshua Simons. 2019. "Small-City Dualism in the Metro Hinderland: The Racialized “Brooklynization" of New York's Hudson Valley." City \& Community 19(1): 1643.

Ramsey, Doug, Alex Michalos and Derrek Eberts. 2016. “Community Changes and Growth in Small Cities: Resident Perceptions of Growth in Brandon, Manitoba, Canada." Growth and Change 47(4): 682-699.

Rice, Gareth. 2009. “Reflections on Interviewing Elites.” Area 42(1): 70-75.

Robertson, Kent A. 1999. “Can Small City Downtowns Remain Viable? A National Study of Development Issues and Strategies." Journal of the American Planning Association 65(3): 270-283.

Rubin, Herbert J. and Irene S. Rubin. 2012. Qualitative Interviewing, The Art of Hearing Data. Thousand, Oaks: Sage Publishing, Inc. 
Segendy, James. 1997. “How Important is 'Quality of Life' in Location Decisions and Local Economic Development." Pp. 56-73 in Dilemmas or Urban Economic Development: Issues in Theory and Practice. Thousand Oaks, CA: Sage Publications.

Siegel, Beth, and Andy Waxman. 2001. "Third-Tier Cities: Adjusting to the New Economy." Reviews of Economic Development Literature and Practice (6): 1-38.

Tritter, Jonathan and Alison McCallum. 2006. "The Snakes and Ladders of User Involvement: Moving Beyond Arnstein." Health Policy 76(2): 156-168.

US Bureau of the Census. 2018. 


\section{APPENDIX A: LETTER TO RESEARCH PARTICIPANTS}

Subject: Invitation to participate in a research project on community development

Dear <name>,

My name is Isabella Green and I am a master's student in the Department of Sociology and Anthropology at Illinois State University.

Under the supervision of Drs. Michael Dougherty and Frank Beck, I am writing my master's thesis on the occupational experiences and perceptions of community leaders in <Woodridge>, and how community input is incorporated into decision-making processes. As a community leader whose expertise is invaluable to my research aims, I am kindly requesting your participation in this study.

If you agree to participate, your involvement would be one 60-minute interview with me that will be scheduled at a time and place convenient to you. Your interview responses and identity will be kept private, and all hard-copies of the data will be kept in an encrypted folder on a password-protected folder. The only information which will be included in the final report is your occupational role in the community.

Your participation in this study would be completely voluntary, and you may choose to withdraw at any point or not answer any questions you feel uncomfortable answering. If you choose to withdraw, all the information you have provided will be destroyed.

There is no compensation for your participation in this study. However, your involvement will be a valuable addition to the future academic studies, and to a greater public understanding of community development and planning.

The ethics protocol for this project was reviewed by Illinois State University Research Ethics Board, which provided clearance to carry out this research. If you have any ethical concerns at any point with this study, please contact the Illinois State University Office of Research Ethics and Compliance at (309) 333-6287 or IRB@ilstu.edu.

Thank you for your interest and consideration. If you are willing to participate, I will send a follow-up email to schedule a date and time, with an ideal time frame being <time frame>. If you have any more questions about the research, please do not hesitate to contact me at $<$ phone number> or igreen@ilstu.edu.

Sincerely,

Isabella Green

ISU Graduate Student

ACED Fellow Sociology Sequence

Email: igreen@ilstu.edu 


\section{APPENDIX B: INFORMED CONSENT FORM}

\section{Consent for Participation in Interview Research}

You are being asked to participate in a research study conducted by Isabella Green, sociology graduate student, and overseen by Drs. Michael Dougherty and Frank Beck, Associate Professors of Sociology, at Illinois State University. The purpose of this study is to interview community leaders in <Woodridge $>$ in order to collect information about their occupational experiences.

The goal of the study is to understand better how economic and planning decision-makers for small cities engage with the various demographic groups that comprise their constituencies.

You have been asked to participate because of your role as a city leader in the $<$ Woodridge $>$ community. If you choose to participate in this study, I will ask you a series of interview questions about your occupation role, recent project pursuits, and interactions with community members.

Your participation in this study is voluntary, and you will not be penalized if you elect not to answer certain questions or to terminate your participation.

Your participation in this study will involve no more than minimal harm or discomfort. Confidentiality cannot be guaranteed because job titles will be divulged in the final report, meaning reidentification is a possibility. In order to minimize recognition of your identity, I have

given pseudonyms to the communities being studied. I will also make every reasonable effort to keep other identifying details private. However, when required by law or university policy, identifying information (including your signed consent form) may be seen or copied by authorized individuals.

The data collected in this study may be disseminated as part of master's thesis, academic journal article, and/or academic presentation.

Your participation in this study will benefit the academic community and will contribute towards future research on community development and planning. The data from this study will also help inform the general public who are interested in these topics.

If you have any questions about the research or wish to withdraw from the study, contact the primary researcher Isabella Green at igreen@ilstu.edu, mobile number <phone number>, or the thesis chair Michael Dougherty at mdoughe@ilstu.edu, office number <phone number>. 
If you have any questions about your rights as a participant, or if you feel you have been placed at risk, contact the Illinois State University Research Ethics \& Compliance Office at (309) 4385527 or IRB@ilstu.edu.

Sign below if you are 18 or older and willing to participate in this study.

Signature Date

Your signature below indicates that you agree to be recorded.

Signature Date

You will be given a copy of this consent form for your records. 


\section{APPENDIX C: SEMI-STRUCTURED INTERVIEW GUIDE}

\section{Sensitizing Concepts:}

- Racial and socioeconomic inequality in the community

- Structure and agency within the local leaders' work

- Communication/Dissemination of information between leaders and the public

\section{Interview Questions:}

1. How did you come to be in the position you have now?

o How long have you been in your current role?

- What are your responsibilities?

2. What are some of the major projects your office is working on?

- Related to transportation? Housing? Business? Community development?

- What are some past major projects?

3. Tell me a little bit about how it's determined which projects or programs are carried out.

- What factors influence which projects and programs are ultimately implemented in the community?

o How do you decide what is a priority?

- Can you walk me through, step by step, what the typical timeline for a project or program is?

- What is the biggest deterrent to a project moving from planning to implementation?

4. Are there any community projects that are currently or recently a point of contention?

- What, if any, discrepancies have there been with past or current projects?

- What kinds of projects have tended to be debated, either amongst community leaders or between community leaders and residents?

5. Tell me a little bit about <Woodridge $>$ as you see it.

- How would you characterized the type of community that $<$ Woodridge $>$ is?

$\circ$ How long have you lived in $<$ Woodridge $>$ ? What drew you to the community?

6. What do the next twenty years look like for <Woodridge $>$ ? The next fifty years?

$\circ$ In terms of community demographics? Transportation options? Housing options? Employment options? Economic trajectory?

- How do you see the community changing, if at all? In what sort of time frame?

- What sorts of information do you have that inform those projected trends?

7. What processes do you use to collect feedback from community residents?

- What physical processes or meetings allow you to collect feedback? Online processes?

- What tends to be your response rate for those opportunities?

- What is your sense of the demographic make-up of those who respond to or attend those opportunities? 
- What factors seem to motivate community members to give feedback? Factors that seem to deter it?

8. How do community demographics influence the work that you do?

- In what ways do you consider race in the work that you do? Class?

o How does the work that you do specifically appeal to younger residents? Older residents? 